\title{
The Effect of Pulse Methylprednisolone Plus Theophylline Treatment on Clinical, Pulmonary and Inflammatory Markers in Relapses of Multiple Sclerosis
}

\author{
Pervin İşeri ${ }^{1}$, Illknur Başyiğit ${ }^{2}$, Çiğdem Özerdem ${ }^{1}$, Hüseyin Başyiğit ${ }^{3}$, Hüsnü Efendi ${ }^{1}$, Füsun Yıldız ${ }^{2}$
}

\author{
${ }^{1}$ Department of Neurology, Faculty of Medicine, Kocaeli University, Kocaeli, Turkey \\ ${ }^{2}$ Department of Chest Diseases, Faculty of Medicine, Kocaeli University, Kocaeli, Turkey \\ ${ }^{3}$ Hospital Pharmacy, Faculty of Medicine, Kocaeli University, Kocaeli, Turkey
}

\begin{abstract}
Objective: The aim of this study was to evaluate whether there was a relationship between severity of multiple sclerosis (MS) exacerbation and pulmonary function test (PFT) and to determine the effect of theophylline, which was added to intravenous methylprednisolone, on serum Tumor Necrosis
\end{abstract} Factor (TNF)-alpha levels and clinical scores in MS relapses.

Study Design: Double blind randomized controlled trial.

Material and Methods: The baseline Expanded Disability Status Scale (EDSS) score was determined, PFT was performed and blood was taken for analysis of TNF- alpha in patients with MS exacerbation. Patients were randomly divided into two groups; group 1 received intravenous methylprednisolone+IV theophylline and group 2 intravenous methylprednisolone+placebo for 5 days. PFT and EDSS score were repeated and blood was taken for TNF-alpha on the $5^{\text {th }}$ and $30^{\text {th }}$ days of the treatment.

Results: Twenty-four patients (14 female, 10 male) were included in the study. Mean age was $32.6 \pm 9$, duration of disease was $5.4 \pm 4.2$ years, number of exacerbations was $5 \pm 2$. There was a significant correlation between the number of exacerbations and EDSS score ( $p=0.000$, $r=1$ ). Restrictive PFT findings were detected in 8 and decrease in carbon monoxide diffusing capacity (DLCO) in 3 cases. In within-group analysis, EDSS score was found to be decreased on day 5 and still low on day 30 in the theophylline group (baseline $3 \pm 1.3 ; 5^{\text {th }}$ day $2.4 \pm 1.6 ; 30^{\text {th }}$ day $2 \pm 1.7$ ). There was no statistically significant difference in the EDSS score of the placebo group $(3 \pm 1.6 ; 2.8 \pm 1.7 ; 2.4 \pm 1.9$ respectively). While serum TNF-alpha level was not changed in the placebo group, there was a non-significant decrease on day 5 and increase on day 30 in the theophylline group. There was no correlation between the clinical parameters, PFT and TNF-alpha level.

Conclusion: There was no correlation between severity of MS and PFT findings. It is suggested that theophylline might be effective in MS exacerbations since it caused decreases in clinical scores; studies with longer treatment duration are needed to clarify its possible anti-inflammatory effect.

Key Words: Multiple sclerosis, inflammation, theophylline, TNF-alpha

Received: $10.10 .2011 \quad$ Accepted: 11.12.2011

\section{Introduction}

Multiple sclerosis (MS) is an inflammatory disease of the central nervous system, in which the type 1 inflammatory response derived by T-lymphocytes and macrophages is thought to play a central role in the destruction of myelin (1, 2). T helper type 1 (Th1) cytokines such as tumor necrosis factor (TNF)-alpha, interleukin (IL)-1, IL-2, IL-12 and interferon (IFN)-gamma are found to be increased both in the blood and the cerebrospinal fluid of MS patients $(2,3)$. Among these cytokines, especially TNF-alpha has been shown to be responsible for myelin and oligodendrocyte damage and correlated with the severity and progression of $\mathrm{MS}(4,5)$.

Since MS is thought to be associated with an imbalance between Th1 and Th2 cytokines, disease-modifying therapies such as IFN-beta have been widely used for the long term treatment (6). Phosphodiesterase inhibitors (PDEI) suppress the catabolism of CAMP and CGMP, thereby they increase intracellular levels of these cyclic nucleotides and modulate the cytokine secretion (7-9). Previous studies have shown that production of Th1 cytokines especially TNF-alpha might be suppressed by PDEI (10-13). PDEI have also been shown to be associated with the decrease in relapse rate and prevention of progression in MS patients (14). To date, 11 isoenzymes of PDE are recognized, however cAMP selective isoenzymes such as PDE4 and PDE3 are thought to be the most important targets in MS $(15,16)$.

Theophylline is a non-selective PDEl and is widely used as a bronchodilator and anti-inflammatory agent in the treatment of inflammatory disease of the airways (16-18). It has also shown that PDEI suppressed TNF-alpha secretion in glial 
cell cultures (4) and decreased the relapse rate in MS patients (14). However, the role of theophylline in the treatment of MS exacerbation was not investigated in previous studies.

In this study, our aim was to evaluate whether addition of theophylline to pulse intravenous methylprednisolone treatment in relapses of MS was associated with improvement in clinical scores and decrease in TNF-alpha levels. We have also evaluated whether there was a relationship between severity of MS relapses and pulmonary function test (PFT).

\section{Material and Methods}

\section{Patients}

In this double blind placebo controlled trial of add-on therapy, 24 patients, 14 female and 10 male, with relapsing-remitting MS having at least one relapse in the past year were recruited. Demographic data of the study population was presented in Table 1. All subjects were diagnosed as having relapsing remitting definite MS according to Mc Donald's criteria (19). Patients were eligible for the study if they had a diagnosis of definite MS and had suffered a relapse, defined as the occurrence, recurrence, or worsening of symptoms of neurological dysfunction lasting more than 24 hours. Fatigue alone and transient feverrelated worsening of symptoms were not considered to be a relapse, and symptoms that occurred within 1 month of each other were considered to be part of the same relapse (20). No patient with MS had received any immunomodulatory or immunosuppressant treatment for at least 3 months prior to the study. Patients had not suffered from any concomitant disease before or during the study. Informed consent was obtained from all subjects. The mean age of the group was (32.6 \pm 9$)$, the mean duration of illness was $(5.4 \pm 4.2)$ years and the number of exacerbations was $5 \pm 2$. Kurtzke's expanded disability status scale (EDSS) was evaluated by a neurologist at the baseline, 5th and 30th days of the treatment.

\section{Study design}

The study was incorporated as a randomized, doubleblind and placebo controlled design. The baseline EDSS score was determined, PFT was performed and blood was taken for analysis of TNF-alpha levels before the study. All patients received intravenous (IV) methylprednisolone (1000 mg/day) treatment. In group 1, IV theophylline (Aminocardol ${ }^{\circledR} 400 \mathrm{mg}$ ampule, Novartis, Basel, Switzerland) was added onto intravenous methylprednisolone treatment, while group 2 received IV placebo (physiological serum) for 5 days. PFT and EDSS score were repeated and blood was taken for TNF-alpha on the $5^{\text {th }}$ and $30^{\text {th }}$ days of the treatment. The serum concentration of theophylline was measured on day 5. EDSS rater neurologist was blinded to the treatment.

The study protocol was approved by the ethics committee and all patients gave written informed consent.

\section{PFT measurement}

Spirometry was performed using a Sensormedics Vmax 20C (Sensormedics, Yorba Linda, CA, USA). Forced expiratory volume in one second $\left(F V_{1}\right)$, forced vital capacity (FVC), $\mathrm{FEV}_{1} / \mathrm{FVC}$ ratio, and vital capacity (VC) were measured. Car- bon monoxide diffusing capacity (DLCO) was also determined using the single-breath $\mathrm{CO}$ method.

\section{TNF-alpha measurement}

Blood was collected in vacutainer tubes and incubated at room temperature for 60-120 minutes. They were then centrifuged at $1300 \mathrm{~g}$ for 10 minutes. The serum was aspirated and stored at $-20^{\circ} \mathrm{C}$ for later analysis. The TNF-alpha levels were assessed by enzyme-linked immunosorbant assay (CytElisa, CYTimmune Sciences, MD, USA). The results were expressed as picogram per liter and adjusted for the dilution factor.

\section{Statistical analysis}

All statistical analyses were performed on SPSS for Windows version 13.0 (SPSS, Chicago, IL, USA). Data were expressed as mean $\pm S D$. Between-group-change outcome variables were determined by the non-parametric Mann-Whitney $U$ test. Within-group-change outcome variables were compared with the Wilcoxon paired test. Symptom scores were determined by chisquared analysis. $\mathrm{p}<0.05$ was considered significant.

\section{Results}

A total of 24 patients were included in the study. Mean age was $32.6 \pm 9$ years, duration of disease was $5.4 \pm 4.2$ years, number of exacerbations was $5 \pm 2$. There was no between group differences with respect to demographic data, baseline EDSS score and pulmonary function test parameters. Baseline serum TNF-alpha levels were higher in the theophylline group compared to placebo, however it was not statistically significant (Table 1).

EDSS score was significantly reduced in the theophylline group while the decrease was not statistically significant in the placebo group (Figure 1). Serum TNF-alpha level did not change significantly in either of the groups. However, there

Table 1. Demographic, clinical, spirometric data of the study population

\begin{tabular}{|lcc|}
\hline & Theophylline & Placebo \\
\hline $\mathrm{N}$ & 12 & 12 \\
Mean age (years) & $30.4 \pm 8.4$ & $34.9 \pm 8.9$ \\
Duration of disease (years) & $5.3 \pm 3.2$ & $5.5 \pm 5.1$ \\
Baseline EDSS score & $3.0 \pm 1.3$ & $3.0 \pm 1.6$ \\
Serum TNF-alpha level (pg/mL) & $1.6 \pm 2.9$ & $0.7 \pm 0.7$ \\
FEV, I (\% predicted) & $2.9 \pm 0.9$ & $2.9 \pm 0.9$ \\
& $(85.9 \pm 19.5)$ & $(87.1 \pm 23.8)$ \\
FVC, I (\% predicted) & $3.5 \pm 1.1$ & $3.3 \pm 1$ \\
& $(86.6 \pm 19.3)$ & $(85.8 \pm 23)$ \\
FEV $/$ FVC (\%) & $85 \pm 8.9$ & $87.1 \pm 5.6$ \\
VC, I (\% predicted) & $3.6 \pm 1.1$ & $3.3 \pm 1$ \\
& $(87.5 \pm 17)$ & $(77.2 \pm 30.5)$ \\
DLCO (\% predicted) & $83 \pm 18.5$ & $82.6 \pm 22.6$ \\
Serum theophylline level ( $\mu \mathrm{g} / \mathrm{dL})$ & $10.7 \pm 7.9$ & $0.5 \pm 0.8$ \\
\hline Forced expiratory volume in one second (FEV $\left.{ }_{1}\right)$, forced vital capacity (FVC), \\
FEV/FVC ratio, vital capacity $(\mathrm{VC})$, carbon monoxide diffusing capacity (DLCO)
\end{tabular}


was a non-significant reduction on $5^{\text {th }}$ day of the theophylline treatment and the TNF-alpha levels increased significantly on day 30 after theophylline was stopped (Figure 2). The EDSS score and levels of TNF-alpha on baseline, day 5 and day 30 in both groups were given in Table 2 .

In the pulmonary function test analysis, restrictive disorder was noticed in 8 patients and DLCO was found to be reduced in 3 patients. There was no significant correlation between the pulmonary function test with EDSS score and TNF-alpha levels. There was a significant correlation between the number of exacerbations and EDSS score $(p=0.000, r=1)$.

\section{Discussion}

Multiple Sclerosis (MS) is a chronic inflammatory demyelinating disorder of the central nervous system. MS is characterised by the presence of demyelinated, sclerotic plaques in the

Table 2. Mean EDSS and TNF-alpha levels of the groups

\begin{tabular}{|llccc|}
\hline & & Theophylline & Placebo & $\mathbf{p}$ \\
\hline EDSS & Baseline & $3.0 \pm 1.3$ & $3.0 \pm 1.6$ & 0.9 \\
& $5^{\text {th }}$ day & $2.4 \pm 1.6$ & $2.8 \pm 1.7$ & 0.5 \\
& $30^{\text {th }}$ day & $2.0 \pm 1.7$ & $2.4 \pm 1.9$ & 0.5 \\
TNF-alpha & Baseline & $1.6 \pm 2.9$ & $0.7 \pm 0.7$ & 0.2 \\
(pg/mL) & $5^{\text {th }}$ day & $0.7 \pm 0.4$ & $1.4 \pm 2.7$ & 0.9 \\
& $3^{\text {th }}$ day & $1.2 \pm 1.1$ & $0.6 \pm 0.3$ & 0.1 \\
\hline
\end{tabular}

EDSS: Expanded disability status scale; TNF: Tumor necrosis factor

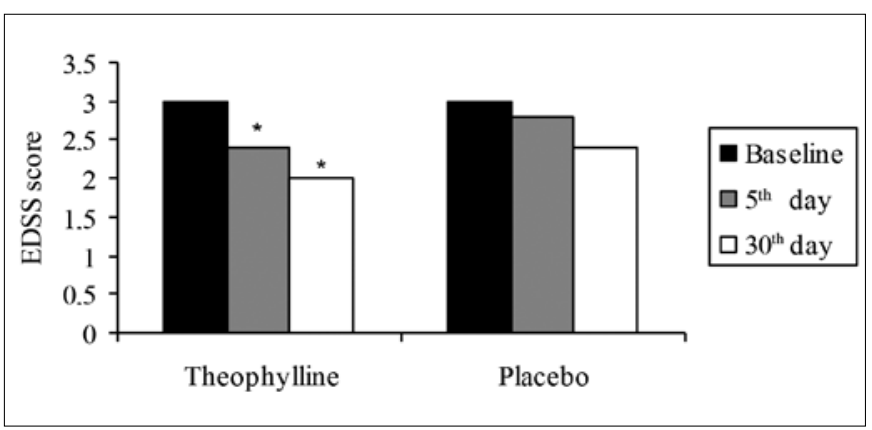

Figure 1. EDSS score of the groups on baseline, $5^{\text {th }}$ and $30^{\text {th }}$ day of treatment

${ }^{*} p<0.05$ statistically significant

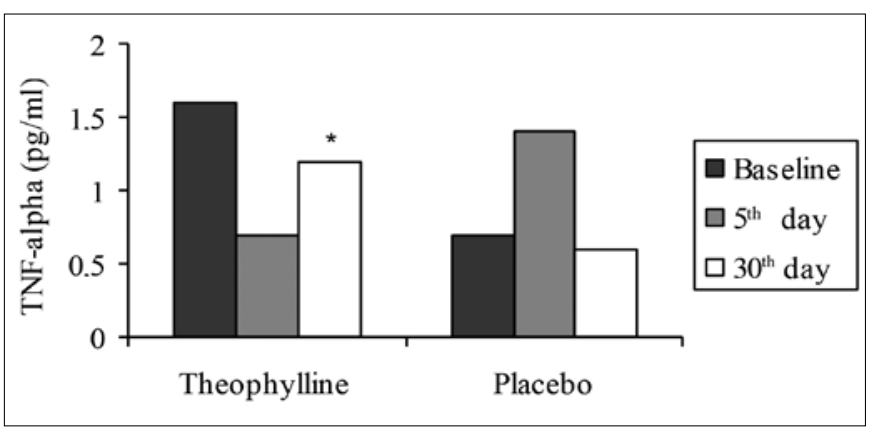

Figure 2. Serum TNF-alpha levels of the groups on baseline, $5^{\text {th }}$ and $30^{\text {th }}$ day of treatment

${ }^{*} p<0.05$ statistically significant central nervous system (CNS). In localised areas of inflammation, oligodendrocytes undergo necrosis and/or apoptosis, which lead to the loss of oligodendrocytes and the development of demyelination. Although the pathogenesis of MS is still unclear, recent studies suggest that proinflammatory cytokines, such as TNF-alpha, play critical roles in the development of the disease as effector molecules (1-3).

TNF-alpha is thought to be one of the mediators responsible for the damage of oligodendrocytes in MS. TNF-alpha is produced by both macrophages and microglia in MS lesions and precedes the production of IL-12. IL-12 promotes the acquisition of a Th1 cytokine profile by CD4/ T cells, which also secrete TNF-alpha (4-5). Specific to autoreactivity, activated myelin basic protein (MBP) -reactive $T$ cells secrete IFN-g, TNF-alpha and IL-2.23. Lymphotoxin (LT, TNF-beta) has also been localized in MS lesions. Therefore, the presence of TNFalpha in MS lesions has been noted and mechanisms for its appearance have been suggested. Also, levels of TNF-alpha correlate with clinical disease progression (4-6). In this study serum TNF-alpha level was not changed in the placebo group, there was a non-significant decrease on day 5 and increase on day 30 in the theophylline group.

Methylprednisolone (MP) plays an important role in the current treatment of multiple sclerosis (MS), particularly in the acute phase of relapse. It acts in various ways to decrease the inflammatory cycle including: dampening the inflammatory cytokine cascade, inhibiting the activation of T cells, decreasing the extravasations of immune cells into the central nervous system, facilitating the apoptosis of activated immune cells, and indirectly decreasing the cytotoxic effects of nitric oxide and TNF-alpha. MP $(21,22,23)$. In this study serum TNF-alpha level was not changed in the placebo group, there was a nonsignificant decrease on day 5 and increase on day 30 in the theophylline group. There was no correlation between the clinical parameters, PFT and TNF-alpha level.

Phosphodiesterases (PDEs) are involved in the regulation of intracellular levels of the second messengers cyclic adenosinemonophosphate (cAMP) and cyclic guanosine monophosphate (cGMP) (15). In the cells of the immune system, increased intracellular levels of cAMP activate protein kinase A (PKA), which is a potent inhibitor of the immune system (12-16). Intracellular cAMP levels are regulated by G-proteincoupled receptors, adenylyl cyclases (ACs) and PDEs (17). In immune cells, cAMP is cleaved predominantly by phosphodiesterases 4 (PDE-4) and 3 (PDE-3) as T-cell activation and cytokine secretion (17-19). Studies with the selective PDE4 inhibitor rolipram have demonstrated the efficacy of the compound in this disease model, suggesting that PDE4 inhibitors could ameliorate the clinical course of MS (10). The effects of the PDE inhibitor pentoxifylline on cytokine production and other immune variables were tested in MS patients. In all studies, efficacy of pentoxifylline in the treatment for MS was not observed (23-25). The within group analysis in this study showed that the EDSS score was decreased on day 5 and still low on day 30 in the theophylline group, there was no statistically significant difference in the EDSS score of the placebo group.

Respiratory complications are common in the terminal stages of multiple sclerosis and contribute to mortality in these patients. Respiratory muscle weakness may also occur early in the course of the disease (26). In the pulmonary function test analysis; restrictive disorder was noticed in 8 patients 
and DLCO was found to be reduced in 3 patients. There was no significant correlation between the pulmonary function test with EDSS score and TNF-alpha levels. Most studies (including ours) that have measured the levels of cytokines and chemokines before and after steroid therapy in MS patients in relapse have not used a not-treatment MS group. A comparison with cytokine levels of not-treated patients in relapse would be useful to determine how the levels evolve in this group of patients. Such a group is very difficult and maybe not be ethical, since most patients with a relapse should start treatment with steroids as soon as possible (19-21).

In this study, there was no correlation between severity of MS and PFT findings, within-group analysis EDSS score was found to be decreased on day 5 and still low on day 30 in the theophylline group, there was no statistically significant difference in the EDSS score of the placebo group. It is suggested that theophylline might be effective in MS exacerbation since it causes decreases in EDSS scores; studies with longer treatment duration are needed to clarify its possible anti-inflammatory effect.

Ethics Committee Approval: Ethics committee approval was received for this study.

Informed Consent: Written informed consent was obtained from patients who participated in this study.

Peer-review: Externally peer-reviewed.

Author contributions: Concept - P.i.; Design - I.B.; Supervision - F.Y.; Resource - P.i.; Materials - H.B.; Data Collection\&/or Processing - Ç.Ö.; Analysis\&/or Interpretation - I.B.; Literature Search - Ç.Ö.; Writing - P.i., I.B., Ç.Ö., H.B., H.E, F.Y.; Critical Reviews - P.I., i.B., Ç.Ö., H.B., H.E, F.Y.

Conflict of Interest: No conflict of interest was declared by the authors.

Financial Disclosure: No financial disclosure was declared by the authors.

\section{References}

1. Hauser SL, Oksenberg JR. The neurobiology of multiple sclerosis:genes, inflammation, and neurodegeneration. Neuron 2006;52:61-76. [CrossRef]

2. Peterson LK, Fujinami RS. Inflammation, demyelination, neurodegeneration and neuroprotection in the pathogenesis of multiple sclerosis. J Neuroimmunol 2007;184:37-44. [CrossRef]

3. Nicoletti F, Di Marco R, Patti F, Zaccone P, L'Episcopo MR, Reggio $E$, et al. Short-term treatment of relapsing remitting multiple sclerosis patients with interferon (IFN)-beta1B transiently increases the blood levels of interleukin (IL)-6, IL-10 and IFN-gamma without significantly modifying those of IL-1beta, IL-2, IL-4 and tumour necrosis factor-alpha. Cytokine 2000;12:682-7. [CrossRef]

4. Kassiotis G, Kollias G. Uncoupling the proinflammatory from the immunosuppressive properties of tumor necrosis factor (TNF) at the p55 TNF receptor level:implications for pathogenesis and therapy of autoimmune demyelination. J Exp Med 2001;193:427-34. [CrossRef]

5. Rieckmann P, Albrecht M, Kitze B, Weber T, Tumani H, Broocks $A$, et al. Tumor necrosis factor-a messenger RNA expression in patients with relapsing-remitting multiple sclerosis is associated with disease activity. Ann Neurol 1995;37:82-8. [CrossRef]

6. Ozenci V, Kouwenhoven M, Huang YM, Kivisäkk P, Link H. Multiple sclerosis is associated with an imbalance between tumour necrosis factor-alpha (TNF-alpha)- and IL-10-secreting blood cells that is corrected by interferon-beta (IFN-beta) treatment. Clin Exp Immunol 2000;120:147-53. [CrossRef]

7. Yoshimura T, Nagao T, Nakao T, Watanabe S, Usami E, Kobayashi J, et al. Modulation of Th1- and Th2-like cytokine production from mito- gen-stimulated human peripheral blood mononuclear cells by phosphodiesterase inhibitors. Gen Pharmacol 1998;30:175-80. [CrossRef]

8. Yoshikawa M, Suzumura A, Tamaru T, Takayanagi T, Sawada M. Effects of phosphodiesterase inhibitors on cytokine production by microglia. Mult Scler 1999;5:126-33. [CrossRef]

9. Moore CS, Earl N, Frenette R, Styhler A, Mancini JA, Nicholson $D W$, et al. Peripheral phosphodiesterase 4 inhibition produced by 4-[2-(3,4-Bis-difluoromethoxyphenyl)-2-[4-(1,1,1,3,3,3-hexafluoro-2-hydroxypropan-2-yl)-phenyl]-ethyl]-3-methylpyridine1-oxide $(L-826,141)$ prevents experimental autoimmune encephalomyelitis. J Pharmacol Exp Ther 2006;319:63-72. [CrossRef]

10. Navikas V, Matusevicius D, Söderström M, Pirskanen R, Fredrikson $\mathrm{S}$, Link $\mathrm{H}$. The phosphodiesterase i.v. inhibitor rolipram in vitro reduces the numbers of MBP-reactive IFN-gamma and TNFalpha mRNA expressing blood mononuclear cells in patients with multiple sclerosis. Clin Neuropharmacol 1998;21:236-44.

11. Dinter H. Phosphodiesterase type 4 inhibitors:potential in the treatment of multiple sclerosis? Biodrugs 2000;13:87-94. [CrossRef]

12. Rieckmann $P$, Weber $F$, Günther $A$, Martin $S$, Bitsch $A$, Broocks $A$, et al. Pentoxifylline, a phosphodiesterase inhibitor, induces immune deviation in patients with multiple sclerosis. J Neuroimmunol 1996;64:193-200. [CrossRef]

13. Feng J, Misu T, Fujihara K, Sakoda S, Nakatsuji Y, Fukaura H, et al. Ibudilast, a nonselective phosphodiesterase inhibitor, regulates Th1/Th2 balance and NKT cell subset in multiple sclerosis. Mult Scler 2004;10:494-8. [CrossRef]

14. Suzumura A, Nakamuro T, Tamaru T, Takayanagi T. Drop in relapse rate of MS by combination therapy of three different phosphodiesterase inhibitors. Mult Scler 2000;6:56-8. [CrossRef]

15. Boswell-Smith V, Spina D, Page CP. Phosphodiesterase inhibitors. Br J Pharmacol 2006;147:252-7. [CrossRef]

16. Anderson M. The properties of aminophylline. Emerg Nurse 2007;15:24-7

17. Yıldırım E, Yıldız F, Özkara SK, Başyiğit I, Boyacı H, llgazlı A. Effects of different combined bronchodilator therapies on airway inflammation in COPD. Clin Drug Invest 2005;25:453-61. [CrossRef]

18. Barnes PJ. Theophylline:new perspectives for an old drug. Am J Respir Crit Care Med 2003;167:813-8. [CrossRef]

19. Polman $\mathrm{CH}$, Reingold SC, Edan G, Filippi M, Hartung HP, Kappos L, et al. Diagnostic criteria for multiple sclerosis:2005 revisions to the "McDonald Criteria". Ann Neurol 2005;58:840-6. [CrossRef]

20. Noseworthy JH. Treatment of relapses and relapsing remitting multiple sclerosis. In:McDonald WI, Noseworthy JH, (eds), Multiple sclerosis 2. Philadelphia:Butterworth-Heinemann;2003. pp.169-91. [CrossRef]

21. Sloka JS, Stefanelli M. The mechanism of action of methylprednisolone in the treatment of multiple sclerosis. Multiple Sclerosis 2005;11:425-32. [CrossRef]

22. Frohman EM, Shah A, Eggenberger E, Metz L, Zivadinov R, Stüve O. Corticosteroids for multiple sclerosis:I. Application for treating exacerbations. Neurotherapeutics 2007;4:618-26. [CrossRef]

23. Dastidar SG, Rajagopal D, Ray A. Therapeutic benefit of PDE4 inhibitors in inflammatory diseases. Curr Opin Investig Drugs 2007;8:364-72.

24. Sommer N, Martin R, McFarland HF, Quigley L, Cannella B, Raine CS, et al. Therapeutic potential of phosphodiesterase type 4 inhibition in chronic autoimmune demyelinating disease. J Neuroimmunol 1997;79:54-61. [CrossRef]

25. Rott O, Cash E, Fleischer B. Phosphodiesterase inhibitor pentoxifylline, a selective suppressor of T helper type 1- but not type 2-associated lymphokine production, prevents induction of experimental autoimmune encephalomyelitis in Lewis rats. Eur J Immunol 1993;23:1745-51. [CrossRef]

26. Altintas A, Demir T, Ikitimur HD, Yildirim N. Pulmonary function in multiple sclerosis without any respiratory complaints. Clin Neurol Neurosurg 2007;109:242-6. [CrossRef] 